\title{
Service provision and functional independence in depressed stroke patients and the effect of social work intervention on these
}

\author{
DEBORAH TOWLE, NADINA B LINCOLN, LOUISE M MAYFIELD \\ From the Stroke Research Unit, General Hospital, Nottingham, UK
}

SUMMARY Objective To compare the provision of health and social services between a social work intervention and non-intervention group.

Design Depressed stroke patients were randomly assigned to either an intervention or nonintervention group. Over a 4 month period both groups were visited three times by an independent assessor who rated them on service provision and functional independence.

Setting Patients' homes.

Patients 44 depressed stroke patients.

Intervention Both groups were given an information booklet and the intervention group were then visited regularly by a research social worker over a period of 4 months. The social worker adopted a pragmatic approach which included providing counselling and information on services and benefits. Main results The study groups did not differ in level of social independence ( $p>0.05)$ or total number of financial benefits $(p>0.05)$, services $(p>0.05)$ or aids $(p>0.05)$ received either before or after intervention. When the results from the two groups were combined, home help and meals-onwheels were the most frequently provided services ( $25 \%$ of patients). Walking aids ( $72 \%$ of patients) and bath aids ( $59 \%$ of patients) were the most frequently provided aids to daily living.

Conclusions Social work assistance had little effect on service provision or level of functional independence.

Several studies have reported on the provision of health and social services for stroke patients. ${ }^{1-4}$ Victor commented that patients who suffer a stroke are more likely than other elderly people discharged from hospital to receive services after discharge. ${ }^{5}$ However, in Garraway's study deficiencies were found in the services provided for stroke patients. ${ }^{\prime}$

Lawrence and Christie ${ }^{6}$ suggested that $40 \%$ of the stroke survivors whom they interviewed 3 years after onset, could have been assisted by a social worker directing them to appropriate community services. The present study was part of an investigation into the effect of social work intervention on depression after stroke. It compares the provision of health and social

Address for reprint requests: Deborah Towle, Stroke Research Unit, General Hospital, Park Row, Nottingham, NG1 6HA, UK.

Received 2 August 1988 and in revised form 3 December 1988. Accepted 12 December 1988 services between a social work intervention and nonintervention group to find whether service provision changes with social work assistance. It was predicted that the social worker would be able to assist patients in terms of providing support services and advising on financial benefits. This in turn might increase their level of social functioning and independence in activities of daily living.

\section{Method}

\section{Subjects}

The subjects were taken from a register of all acute stroke admissions to the City, General and University hospitals, Nottingham. Patients were excluded if they; (1) were less than one year post stroke; (2) had a history of dementia or confusion or confused at the time of contact; (3) were still in hospital or residential homes; (4) were unable to respond to questionnaires either verbally or by writing.

The selected patients were sent the General Health Questionnaire [GHQ], ${ }^{7}$ and the Wakefield Depression Inventory 
[WDI], ${ }^{8}$ through the mail. Patients were included in the study if they scored 10 or more on the GHQ or 18 or more on the WDI, which identified them as having depressed mood. These cut-offs are higher than the 5 or more suggested for the $\mathrm{GHQ}^{7}$ and 14-16 for the WDI, ${ }^{8}$ because only the most depressed patients were to be included.

\section{Procedure}

The depressed patients were visited at home by an independent assessor (DT) who administered a series of questionnaires. These included:-

1. Services Questionnaire: a checklist of medical and social services received, visits by family members and attendence at clubs and centres.

2. Aids/Adaptations checklist: a checklist of aids to daily living and adaptations received and their usefulness.

3. Financial benefits questionnaire: a list of financial benefits received by the patient and carer. These included invalidity benefit or pension; retirement pension; supplementary benefit or pension; attendance allowance; invalid care allowance; mobility allowance; housing benefit and work pensions.

4. Extended Activities of Daily Living Questionnaire $(E A D L)^{9}:$ a ranked scale assessing 22 activities grouped into four categories: mobility, kitchen, domestic and leisure, and scored in terms of what the patients do rather than what they are capable of.

5. Frenchay Activities Index (FAI $)^{1011}$ : an assessment of social functioning.

The patients were then allocated randomly to one of two groups using sealed envelopes each containing a slip of paper stating either "treatment" or "no treatment". The order of the envelopes had been decided before the study using random number tables.

Patients in Group 1 (no treatment) were visited once only by the research social worker (LM) and given an information booklet developed for the purpose of the study and covering subjects thought to be of use and interest to stoke survivors and their families. It included the addresses of local stroke clubs, social services and occupational therapy departments; and descriptions of available financial benefits and how to deal with problems such as incontinence.

Patients in Group 2 (treatment) as well as receiving the information booklet, were visited by the research social worker up to twice a week for 16 weeks. As problems varied from one patient to the next the social worker adopted a pragmatic approach taking whatever action was necessary including advising on services and benefits; contacting local day centres and providing counselling.

Each patient was visited 8 weeks and 16 weeks later by the independent assessor who repeated the pre-intervention questionnaires.

\section{Results}

\section{Patients}

Of the 209 questionnaires sent out, 45 patients had died and 41 did not reply. The GHQ and WDI were completed by 123 patients. Fifty-six (45.5\%) scored as depressed. Of these two died, one was seriously ill, one suffered from confusion, two refused to take part and a relative had completed the questionnaires for one patient who was dysphasic. The assessor was unable to follow-up five patients as the study had to come to an end. Forty-four depressed stroke patients were included in the study. They ranged from 50 to 81 years of age (mean 69.0 years, SD 7.9) and included 25 men. All were between 16 and 39 months post onset. Six patients were taking antidepressants.

Differences were analysed between groups using Mann-Whitney $U$ tests and within groups using Wilcoxon Signed Ranks tests.

\section{Evaluation of social work intervention}

There was no difference between the "treatment" and "no treatment" groups in the total number of financial benefits received either before $(U=238.0, p>0.05)$ or after intervention $(U=185.0, p>0.05)$. The two groups did not differ in level of social independence as measured by the EADL $(U=158.0, p>0.05)$ or the FAI $(U=197.0, p>0.05)$ at the beginning of the study or following treatment (EADL $U=190.0$, $\mathrm{p}>0.05 \mathrm{FAI} \mathrm{U}=211 \cdot 0, \mathrm{p}>0.05)$.

It was not possible to compare statistically the groups on each service or aid received because of the small numbers of subjects in each response category, and instead the total number was compared. The two groups did not differ in the number of services $(\mathrm{U}=228.0, \mathrm{p}>0.05)$ or aids $(\mathrm{U}=202.5, \mathrm{p}>0.05)$ provided before intervention. Social work assistance did not produce a statistically significant differencen between the groups in total number of services $(U=209.5, p>0.05)$ or aids $(U=192.5, p>0.05)$ received.

When change over time within groups was examined the number of benefits received had increased in both groups ("treatment" $W=11.0$, $\mathrm{p}<0.01$, "no treatment" $\mathrm{W}=12.0, \mathrm{p}<0.01$ ). However, the amount of change did not differ between groups $(z=0.87, p>0.05)$.

As the groups did not differ, their results were combined. Most patients had received some outpatient physiotherapy $(\mathrm{n}=26,59 \cdot 1 \%)$, a medical outpatient appointment $(n=24,54.5 \%)$ and some contact with a social worker $(n=24,54.5 \%)$ after leaving hospital. The most frequently provided services were home helps and meals-on-wheels but only a quarter of the patients $(n=11)$ received either of these. The majority of patients $(41,93.2 \%)$ had visited their doctor's surgery. Of those patients not receiving medication, two had not seen their doctor since leaving hospital. Almost all subjects $(n=43$, $97 \cdot 7 \%$ ) had contact with members of their family, and $56.8 \%(n=25)$ of patients saw another family member more than once a week.

The most frequently provided aids were the walking stick $(n=32,72 \cdot 7 \%)$ and bath aids $(n=26,59 \cdot 1 \%)$. The type of aids received and the reported usefulness of these is shown in the table. 
Table Use of aids to daily living by depressed stroke patients

\begin{tabular}{|c|c|c|c|c|c|}
\hline \multirow[b]{3}{*}{$A I D$} & \multicolumn{3}{|c|}{ Use of aids $n(\%)$} & & \\
\hline & \multirow{2}{*}{$\begin{array}{l}\text { Awaiting } \\
\text { delivery }\end{array}$} & \multirow{2}{*}{$\begin{array}{l}\text { Not been offered } \\
\text { but would be } \\
\text { interested }\end{array}$} & \multirow[b]{2}{*}{ Do not need } & \multicolumn{2}{|c|}{ Received and Reported Usefulness } \\
\hline & & & & Not useful & Useful \\
\hline $\begin{array}{l}\text { Bath Aids } \\
\text { Toilet Aids } \\
\text { Stair Rail } \\
\text { Grab Handles } \\
\text { Walking Stick } \\
\text { Wheelchair } \\
\text { Ramps } \\
\text { Bed/Chair Raise } \\
\text { Kitchen Aids } \\
\text { Eating Aids } \\
\text { Dressing Aids } \\
\text { Nursing Aids (eg incontinence pads) } \\
\text { Telephone } \\
\text { Alarm Call System }\end{array}$ & $\begin{array}{l}0(0) \\
0(0) \\
2(4 \cdot 5) \\
0(0) \\
1(2 \cdot 3) \\
0(0) \\
1(2 \cdot 3) \\
0(0) \\
0(0) \\
0(0) \\
0(0) \\
0(0) \\
0(0) \\
1(2 \cdot 3)\end{array}$ & $\begin{array}{l}3(6 \cdot 8) \\
1(2 \cdot 3) \\
2(4 \cdot 5) \\
5(11 \cdot 4) \\
3(4 \cdot 5) \\
3(6 \cdot 8) \\
2(4 \cdot 5) \\
1(2 \cdot 3) \\
8(18 \cdot 2) \\
7(15 \cdot 9) \\
5(11 \cdot 4) \\
1(2 \cdot 3) \\
4(9 \cdot 1) \\
5(11 \cdot 4)\end{array}$ & $\begin{array}{l}15(34 \cdot 2) \\
24(54 \cdot 5) \\
28(63 \cdot 7) \\
23(52 \cdot 3) \\
24(20 \cdot 5) \\
24(54 \cdot 5) \\
34(77 \cdot 3) \\
30(68 \cdot 2) \\
31(70 \cdot 5) \\
26(59 \cdot 1) \\
34(77 \cdot 2) \\
38(86 \cdot 3) \\
33(75 \cdot 0) \\
36(81 \cdot 8)\end{array}$ & $\begin{array}{l}2(4 \cdot 5) \\
3(6 \cdot 8) \\
1(2 \cdot 3) \\
2(4 \cdot 5) \\
4(9 \cdot 1) \\
5(11 \cdot 4) \\
1(2 \cdot 3) \\
3(6 \cdot 8) \\
2(4 \cdot 5) \\
1(2 \cdot 3) \\
1(2 \cdot 3) \\
0(0) \\
1(2 \cdot 3) \\
0(0)\end{array}$ & $\begin{array}{l}24(54 \cdot 5) \\
16(36 \cdot 4) \\
11(25 \cdot 0) \\
14(31 \cdot 8) \\
28(63 \cdot 6) \\
12(27 \cdot 3) \\
6(13 \cdot 6) \\
10(22 \cdot 7) \\
3(6 \cdot 8) \\
10(22 \cdot 7) \\
3(9 \cdot 1) \\
5(11 \cdot 4) \\
6(13 \cdot 6) \\
2(4 \cdot 5)\end{array}$ \\
\hline
\end{tabular}

Factors affecting service provision

Age: Patients receiving home help $(U=78.5$, $\mathrm{p}<0.01)$, meals-on-wheels $(\mathrm{U}=99.5, \mathrm{p}<0.05)$ and day hospital care $(U=63.0, p<0.05)$ were significantly older than those not receiving these services.

Duration of hospital stay: When length of hospital stay in weeks was examined those patients provided with home help $(U=78.5, p<0.05)$, meals-on-wheels $(U=99.5, p<0.05)$, day hospital care $(U=66.5$, $\mathrm{p}<0.05)$, bath nurse assistance $(\mathrm{U}=56.0$, $\mathrm{p}<0.01)$, day centre places $(U=81.5, p<0.01)$ and who attended stroke clubs $(U=19.0, p<0.05)$ had spent significantly longer in hospital following the stroke.

Dependency in $A D L$ The total EADL scores were compared for those patients receiving and not receiving services, to examine the effect of disability on service provision. Those provided with outpatient physiotherapy $(U=124.5, p<0.01)$, day hospital care $(U=66.0, p<0.05)$, hospital relief care $(\mathrm{U}=4.0, \quad \mathrm{p}<0.01)$, bath nurse assistance $(\mathrm{U}=49.5, \mathrm{p}<0.001)$ and who attended stroke clubs $(U=17.5, p<0.05)$ or day centres $(U=80.5$, $\mathrm{p}<0.01)$ required significantly more help with activities of daily living.

\section{Discussion}

In Garraway et al's study of service provision' a check was made on the accuracy of patients reports but in the present study we did not do this. We must assume that our respondents were accurate, and the elderly do appear to be reliable reporters of the services they receive. $^{s}$

Social work assistance for a period of 4 months did not produce any significant difference in the total number of benefits claimed, aids received or level of independence reached by the patients. However, it must be noted that sample size was small and there may have been effects not detected by the study. Areas, such as attitudes of the patients to their disability, were not assessed but could have been affected. The information booklet or the questionnaires used may have contributed to the changes which took place in both groups by drawing patients' attention to available services and benefits.

When the results from the two groups were combined, almost half the patients had never attended an outpatient clinic and the majority did not receive any occupational therapy once they had left hospital, but most were not interested in these services. The therapy most frequently received and requested was physiotherapy as patients believed that with some additional therapy their disabled limbs would improve. Three patients, despite being more than one year since their strokes, were receiving physiotherapy or occupational therapy more than once a week.

General Practitioners (GPs) had the opportunity of seeing the highest proportion of patients at least once after the stroke, but visits to the surgery were generally for repeat prescriptions. Ebrahim et al ${ }^{3}$ suggested GPs may be able to co-ordinate services required by patients, but this seems unlikely unless they see stroke patients more regularly. The infrequency of visits to GPs may explain the low number of patients on antidepressants although it can not be judged from the present study which patients would have been suitable for this treatment. Wade reported that antidepressants are not given to stroke patients who appear depressed when assessed on self-report inventories. ${ }^{12}$

When examining why patients do not make use of services, the quality of these needs to be considered. Meals-on-wheels were cancelled by several patients 
because of the poor choice and quality of the meals. Offers of help at time of discharge from hospital may be rejected with patients later changing their minds. Patients often expressed an interest in stroke clubs but reported that information was lacking about the clubs and who they were intended for. Concern was also expressed about travelling to them as few patients used buses or could afford taxis and were unaware of the volunteer driver service. Stroke clubs and the volunteer driver services need to be more widely advertised.

Many patients managed without the help of aids or adaptations and wanted to continue without them. Those with bath aids often felt that alone they were not enough and extra physical help, perhaps more for reassurance, would have been welcomed. Five patients possessing wheel chairs found them to be of little use as the patient was too heavy to push, especially uphill. This factor needs to be considered when prescribing this aid. The newly opened Resource Centre in Nottingham may increase the availability of aids to daily living, providing patients can travel to the Centre.

In the present sample patients receiving services tended to be older, more disabled and to have stayed in hospital for longer. A relationship between provision and social isolation might be expected. However, when social isolation was measured on part on the Nottingham Health Profile (unpublished) no such relationship was found. Attending clubs or day centres does not appear sufficient to prevent feelings of isolation.

In conclusion, when the study groups were compared on various measures, social work assistance had little effect. It was not that patients were content with services as they often complained about the infrequency of these and lack of advice given concerning financial benefits. A possible explanation for the lack of difference is that although services such as physiotherapy were requested they were no longer appropriate for the patient. The small sample size, possible use of inappropriate measures, and the pragmatic approach adopted by the social worker may have contributed to the negative findings. Further studies are needed of the contribution of social work, in particular with depressed stroke patients within 6 months of discharge from hospital, with stroke patients who are not depressed and with those requiring more prolonged or intensive support. The provision of an information booklet, which draws attention to services, also requires evaluation.

We thank the Chest, Heart and Stroke Association and the Nottingham Fights Stroke Appeal for their financial support, Mrs A Dudley for help with manuscript preparation, and Dr D Barer for access to the stroke register.

\section{References}

1 Garraway WM, Walton MS, Akhtar AJ, Prescott RJ. The use of health and social services in the management of stroke in the community: Results from a controlled trial. Age Ageing 1981;10:95-104.

2 Legh-Smith J, Wade DT, Langton-Hewer R. Services for stroke patients one year after stroke. $J$ Epidemiol Commun Health 1986;40:161-5.

3 Ebrahim S, Nouri F. Caring for stroke patients at home. Int Rehabil Med 1987;8:171-3.

4 Ebrahim S, Barer DB, Nouri F. An audit of follow-up services for stroke patients after discharge from hospital. International Disability Studies 1987;9:103-5.

5 Victor CR, Vetter HJ. Use of community services by the elderly 3 and 12 months after discharge from hospital. Int Rehabil Med 1985;7:56-59.

6 Lawrence L, Christie D. Quality of life after stroke. A three year follow-up. Age Ageing 1979;8:167-72. .

7 Goldberg DP, Hillier VF. A scaled version of the General Health Questionnaire. Psychol Med 1979;9:139-45.

8 Snaith RP, Ahmed SN, Mehta S, Hamilton M. Assessment of the severity of primary depressive illness. Wakefield Self-assessment Depression Inventory. Psychol Med 1971;1:143-9.

9 Nouri FM, Lincoln NB. An extended activities of daily living scale for stroke patients. Clin Rehabil 1987; 1:301-5.

10 Holbrook M, Skilbeck CE. An activities index for use with stroke patients. Age Ageing 1983;12:166-70.

11 Wade DT, Legh-Smith J, Langton-Hewer R. Social activities after stroke: Measurement and natural history using the Frenchay Activities Index. Int Rehabil Med 1985;7:176-81.

12 Wade DT, Legh-Smith J, Langton-Hewer R. Depressed mood after stroke: A community study of its frequency, prognosis and associated factors. $B r J$ Psychiatry 1987;151:200-5. 